\title{
Synchronous Growth of Rhodopseudomonas palustris from the Swarmer Phase
}

\author{
By D. WESTMACOTT* AND S. B. PRIMROSE \\ Department of Biological Sciences, University of Warwick, Coventry CV4 $7 A L$
}

(Received 8 September 1975; revised 26 November 1975)

\begin{abstract}
SUMMARY
Rhodopseudomonas palustris was chosen as a model organism for studying bacterial differentiation. Synchronous populations selected by sucrose gradient centrifugation yielded more than $95 \%$ swarmer cells. The appearance and disappearance of cell morphological groupings and the doubling of cell numbers in cultures of such swarmer populations were very well defined. Cells were only motile for the first half of the division cycle, but motility was regained before division. Development gave rise to a distinct and characteristic pattern of extinction increase and particle volume distribution. The development of swarmers into mother cells and the dimorphic division of $R$. palustris are discussed as simple examples of differentiation.
\end{abstract}

\section{INTRODUCTION}

In most bacterial species the only evident morphogenesis in the cell cycle is division. There are, however, a number of bacteria that display more complex cycles and therefore offer themselves as potential models for studying the control of simple developmental pathways. Not least of these are the photosynthetic budding bacteria, Rhodopseudomonas acidophila, Rhodopseudomonas palustris and Rhodomicrobium vannielii, which exhibit a gradient of morphogenetic complexity (C. S. Dow, D. Westmacott and R. Whittenbury, unpublished observations). The morphological development of $R$. palustris was described as a life cycle by Whittenbury \& McLee (1967) and is summarized in Fig. I. The daughter cell (a) develops a short, blunt-ended, phase contrast-translucent tube $(b, c)$ which is slightly narrower than the original cell. At the end of the tube a swelling, or bud, develops (d) which eventually gives the whole structure a dumbell shape (e). Division takes place between the end of the tube and the daughter cell that has developed (f). The daughter can be motile under suitable conditions, whilst the cell with a tube (mother) is non-motile and has a sticky 'holdfast' at the opposite pole to the tube. Thus the cell cycle of $R$. palustris is in many respects similar to that of Hyphomicrobium neptunium (Leifson, 1964).

The non-budding prosthecate bacterium, Caulobacter, was described by Stove \& Stanier (1962) as forming appendaged mother cells with holdfasts and motile daughter cells. Although Caulobacter has been used as a model of differentiation (Shapiro, Agabian-Keshishian \& Bendis, 197I), it lacks the attractive features of inducible synthesis of photosynthetic membranes and development within a range of related but morphologically different organisms. Similar arguments may be made about Hyphomicrobium, the division cycle of which has been studied in synchronous populations (Moore \& Hirsch, 1973).

This paper presents information on the degree of synchrony achieved by selecting populations of $R$. palustris swarmer cells, and also describes some of the morphogenetic changes that occur during the division cycle.

* Present address: Department of Microbiology, University of Liverpool, Liverpool L69 3BX. 


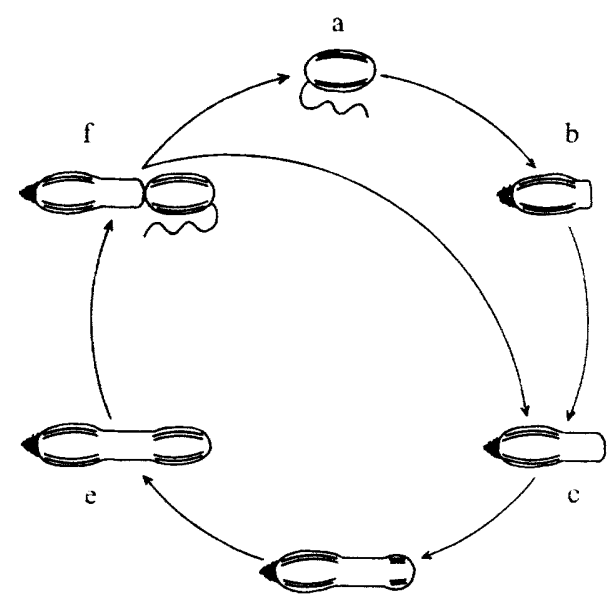

d

Fig. I. Diagrammatic representation of the division cycle of $R$. palustris. Developmental stages are described in the text.

\section{METHODS}

Organism and cultivation. A $R$. palustris strain isolated from fresh water by Dr C. S. Dow (Department of Biological Sciences, University of Warwick) was used in all experiments. PAYE medium for the cultivation of $R$. palustris was prepared as described by Westmacott \& Primrose (1975), omitting the agar in order to prepare liquid media. Routine $100 \mathrm{ml}$ liquid cultures were grown in $250 \mathrm{ml}$ conical flasks, which had ground-glass necks and were fitted with standard turnover-type Suba-Seals (William Freeman \& Co. Ltd, Barnsley, Yorkshire). Flasks were gassed for about $10 \mathrm{~min}$ with oxygen-free nitrogen and incubated at $34{ }^{\circ} \mathrm{C}$. Illumination was provided by a $100 \mathrm{~W}$ tungsten bulb placed at a distance of $30 \mathrm{~cm}$ (approximately 4000 lux) using an adjustable desk lamp.

Selection of synchronous cells. Synchronous populations of swarmer cells were isolated by a modification of the sucrose gradient sedimentation technique of Mitchison \& Vincent (1965). The cells from 75 to $100 \mathrm{ml}$ of mid-exponential culture were concentrated 25 -fold by centrifugation and layered on top of a $30 \mathrm{ml}$ linear sucrose gradient $(7.5$ to $15 \%, \mathrm{w} / \mathrm{v}$, sucrose in PAYE). Centrifugation was for $9 \mathrm{~min}$ at $3300 \mathrm{rev} . / \mathrm{min}$ (approximately $4200 \mathrm{~g}$ ) using the swing-out rotor of an MSE Multex centrifuge. The swarmer cells were found in the uppermost layers of the band of cells, about one-third of the way down the gradient. By removing $\mathrm{I} .8 \mathrm{ml}$, or less, of this part of the gradient, up to $2.5 \times 10^{9}$ synchronous cells were obtained.

Slide culture and light microscopy. PAYE agar was boiled for $30 \mathrm{~min}$ under a continuous flow of oxygen-free nitrogen, and phosphate buffer was added after it had cooled to about $70{ }^{\circ} \mathrm{C}$. Two drops of agar were placed on a sterile microscope slide in a sandwich box which was continuously gassed with oxygen-free nitrogen. The agar was covered with a sterile coverslip in order to produce a thin, flat film of agar. After 5 to 10 min the coverslip was carefully removed and the agar inoculated with a drop of cell suspension. A fresh sterile coverslip was placed on the agar and sealed on to the slide with a mixture of petroleum jelly and paraffin wax.

Microscopy of slide cultures was carried out on a Leitz Orthoplan microscope fitted with a Heine phase-contrast condenser and a Leitz heating and cooling stage 8o. Slide cultures 
were incubated at $34^{\circ} \mathrm{C}$ and illuminated with a $100 \mathrm{~W}$ bulb from a distance of $30 \mathrm{~cm}$ (approximately 4000 lux). Photomicrographs were taken on Kodak Panatomic-X film using a Leitz Orthomat camera for slide cultures and an Olympus PM-6 camera on an Olympus EHT microscope (Olympus Optical Co. Ltd, Tokyo, Japan) for culture samples.

Coulter counter analysis. The frequency distribution of particle volumes in samples from liquid cultures was determined using a model ZF Coulter counter (Coulter Electronics Ltd, Dunstable, Bedfordshire) together with a Coulter Channelyzer and XY Recorder II. Samples were diluted roo-fold in phosphate buffer and particle counts made immediately on a subsequent I0-fold dilution of each sample in Isoton (Coulter Electronics Ltd) using a $30 \mu \mathrm{m}$ aperture. Frequency distributions of particle volumes were accumulated in the Channelyzer over arbitrary periods of sample analysis before being printed out on the recorder. Total particle counts were made on $0.05 \mathrm{ml}$ samples of the Isoton dilutions and the mean of six counts converted to particles per millilitre of synchronous culture.

Extinction measurements. Alcohol-sterilized $1 \mathrm{~cm}$ glass cuvettes, fitted with standard turnover-type Suba-Seals, were used to grow 3.5 to $4.0 \mathrm{ml}$ cultures. After gassing for $2 \mathrm{~min}$ with nitrogen, the cultures were incubated at $34{ }^{\circ} \mathrm{C}$ and illuminated at 4000 lux. Changes of extinction were followed by periodic estimations of $E_{500}$ using a Pye-Unicam SP500 spectrophotometer.

\section{RESULTS}

\section{Synchrony of growth}

When a heterogeneous population of $R$. palustris was centrifuged in a sucrose gradient as described in Methods, the uppermost layer of cells was found to contain almost exclusively swarmer cells (Fig. 2). By examining a single field of a slide culture at time intervals after inoculation with swarmers obtained in this way, a well-defined synchronous development and division (Fig. 3), with concomitant increase in cell numbers after $7 \cdot 25 \mathrm{~h}$ (Fig. 4), was observed. Thus development of individual cells proceeded as described by Whittenbury \& McLee (1967) and morphogenetic events appeared to occur in most cells at the same time. During the second generation, the increase in cell numbers was biphasic. This was because first generation swarmer cells have to synthesize a tube before producing a daughter bud, whilst mother cells bud directly on their pre-formed tube. Liquid cultures of swarmers also undergo a synchronous cell division, but this usually occurs about $\mathrm{I} \cdot 75 \mathrm{~h}$ earlier and presumably reflects physiological differences between the liquid and agar cultures. A careful examination of development with time seemed to indicate that the extended first doubling time on slide culture was a result of an initial lag in development. However, once development had started growth proceeded as rapidly as in liquid culture. Thus the second generation swarmer doubling time in the slide culture lasted about $5.25 \mathrm{~h}$, just as it did in comparable first-generation liquid cultures.

An examination of more than 400 cells in samples from a synchronous liquid culture revealed that there was a tight grouping of appearance and disappearance of swarmers, cells with tubes, budding cells and cells having a division constriction (Fig. 5). Initially more than $95 \%$ of cells examined were swarmers and they remained as such for about $2 \mathrm{~h}$. It was consistently observed that such a period of swarmer maturation occurred during development of synchronous $R$. palustris cultures. Tube elongation lasted for about $\mathrm{I} \cdot 5 \mathrm{~h}$ and bud formation also about $\mathrm{I} \cdot 5 \mathrm{~h}$. Even during bud formation, there was still a peak of about $90 \%$ of examined cells all being in one stage of development at the same time. A majority of dividing cells (having division constrictions) was never observed since this stage in development was so short-lived, but the period of maximum cell division was seen as a 


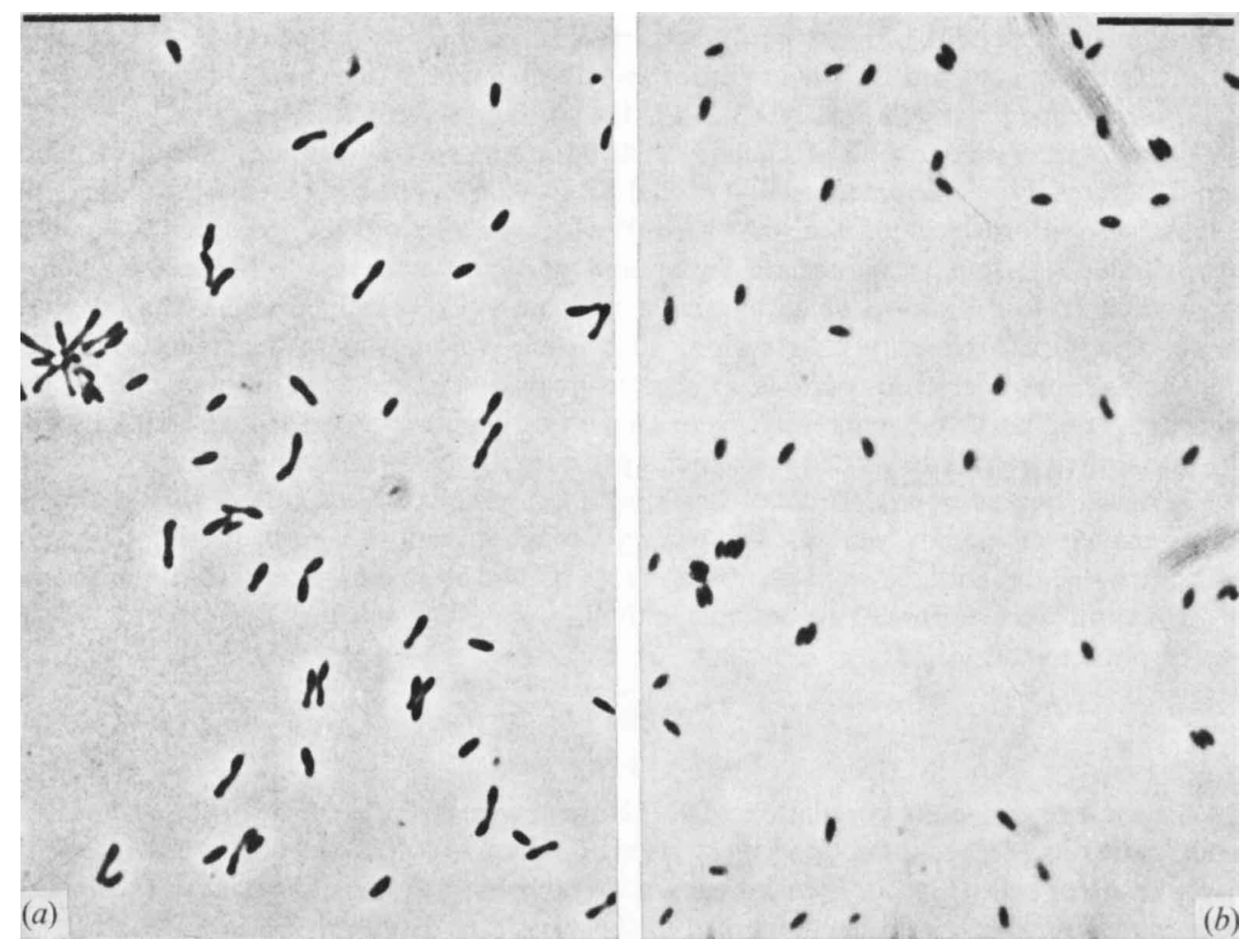

Fig. 2. Phase-contrast photomicrographs of $(a)$ a heterogeneous population and $(b)$ a synchronous swarmer population of $R$. palistris. Bar markers represent io $\mu \mathrm{m}$.

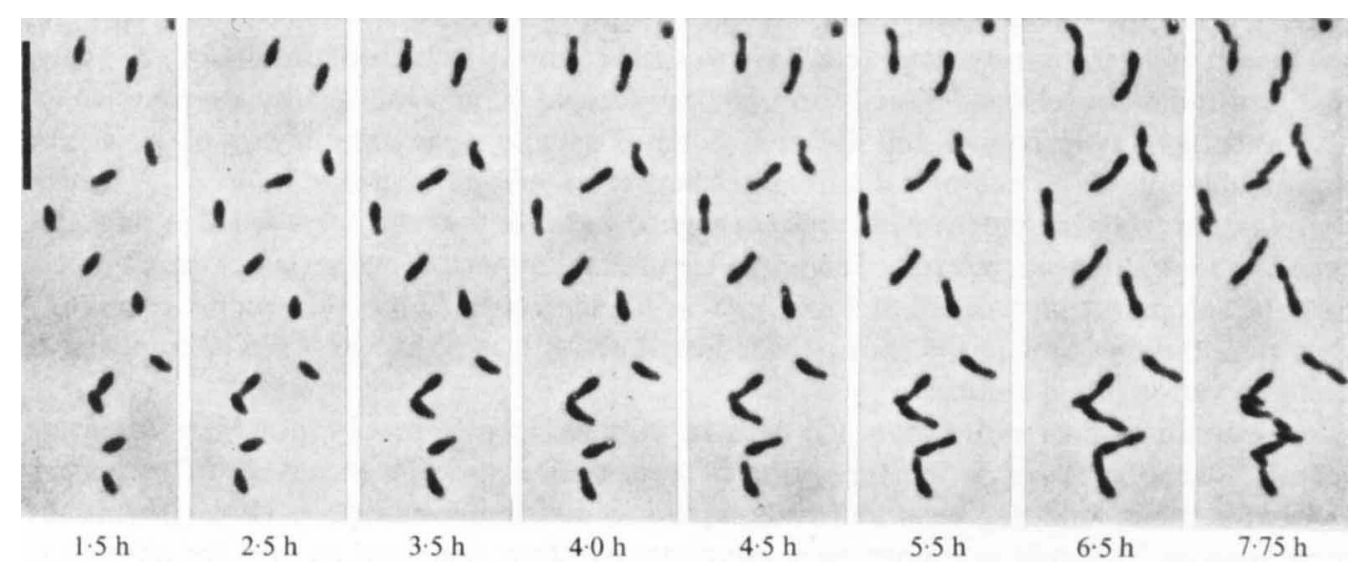

Fig. 3. Phase-contrast photomicrographs of a group of synchronously growing $R$. palustris cells. Bar marker represents $10 \mu \mathrm{m}$. 


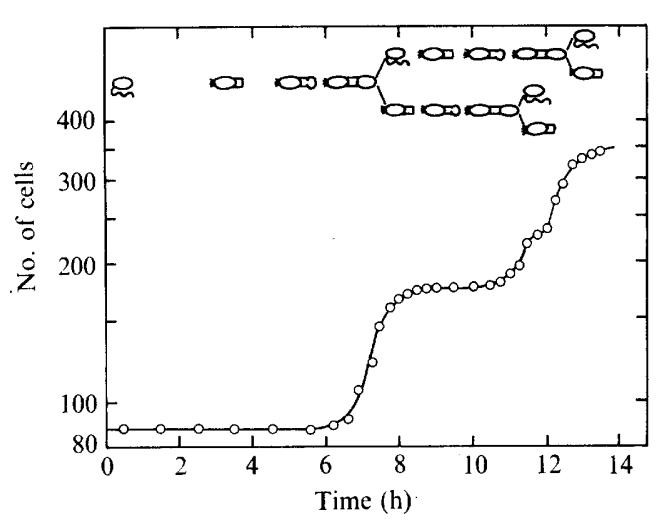

Fig. 4

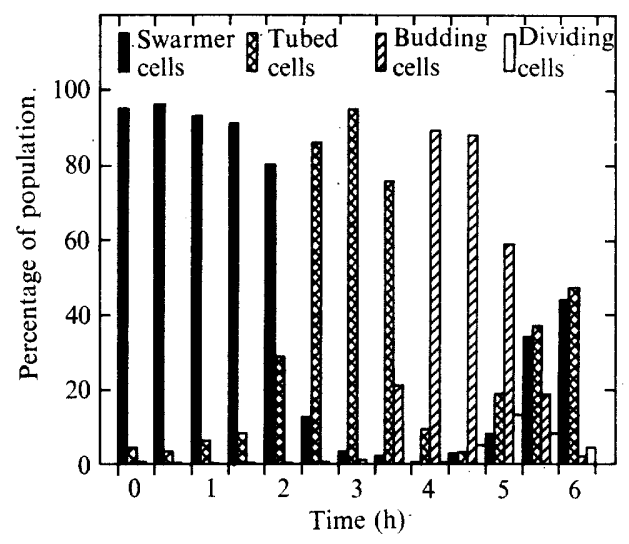

Fig. 5

Fig. 4. Stepwise increase in cell numbers in a synchronous culture of $R$. palustris. The number of individual cells was followed in a field of a slide culture of swarmer cells.

Fig. 5. Distribution of swarmer cells, cells with tubes, budding cells and dividing cells (those with a visible constriction) during synchronous liquid culture of $R$. palustris. At half-hour intervals more than 400 cells were classified into the four morphological groupings; numbers are expressed as a percentage of the total counted.

new combined increase in swarmers and cells with tubes (mother cells), as well as a small peak of dividing cells.

\section{Motility}

The proportion of motile cells in a synchronous liquid culture of $R$. palustris was estimated by examining sample cell suspensions in a bacterial counting chamber (Fig. 6). Although the method did not permit accurate quantitative analysis, it did clearly demonstrate that the swarmers were highly motile but lost this property during the development of the tube. Thus some overlap was seen between loss of motility and holdfast synthesis, explaining the frequent observation of rapidly rotating motile cells which were stuck to the slide or coverslip by their holdfasts. Motility had, however, been almost completely lost by the stage of bud formation, and the cells remained non-motile till just before cell division, when motile swarmers could be seen 'towing' their non-motile mother cells behind them. At division the proportion of motile cells dropped, since half of the population were non-motile mother cells.

\section{Extinction}

Changes in $E_{500}$ of a heterogeneous and a synchronous cuvette culture of $R$. palustris were followed (Fig. 7). As expected, there was an approximately logarithmic increase in the extinction of the heterogeneous control; however, that of the synchronous culture increased in three distinct phases. Initially there was a period of rapid increase lasting about $\mathrm{I} \cdot 5 \mathrm{~h}$ and corresponding to swarmer maturation. Note that the extinction increased from zero time, suggesting that there was no lag in the initiation of development in the swarmer cells. This was followed by a further $\mathrm{I} \cdot 5 \mathrm{~h}$ period, corresponding to tube elongation, in which the increase was substantially reduced. During bud formation the rate of extinction increase returned to a higher level which lasted until division. It is difficult to be certain precisely in what way the cell development affected the extinction, although it does seem unlikely that increased extinction is a result of periodic photopigment synthesis. The only pigment 


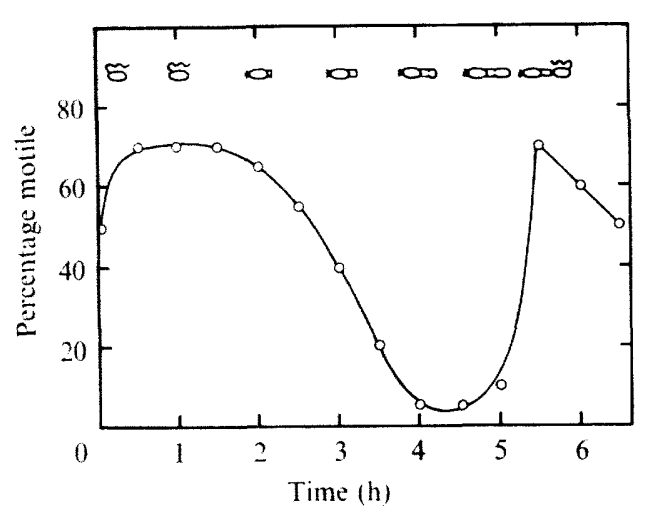

Fig. 6

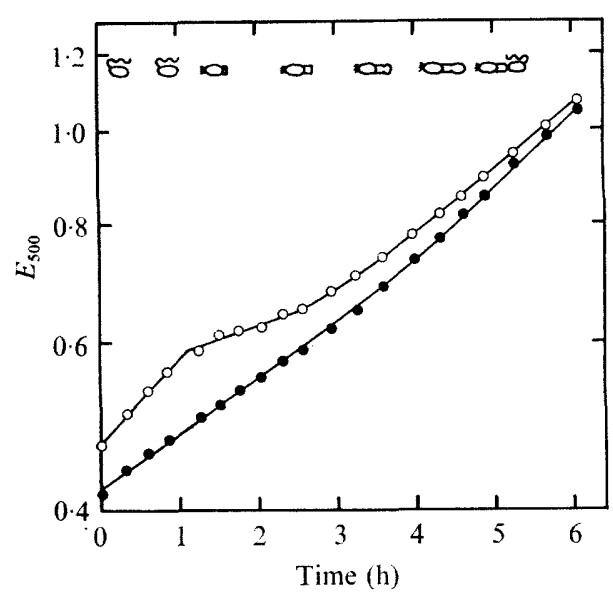

Fig 7

Fig. 6. Motility of $R$. palustris during synchronous liquid culture. The proportion of motile cells was estimated visually at half-hour intervals. The morphology of the synchronous culture is represented diagrammatically.

Fig. 7. Extinction changes in a synchronous culture of $R$. palustris. $E_{500}$ was compared in synchronous $(O)$ and heterogeneous $(O)$ cuvette cultures. Morphological development in the synchronousculture is shown diagrammatically.

absorption peaks that are seen in spectra of cells suspended in nutrient medium are two small infra-red peaks due to absorption by bacteriochlorophyll $a$. The extinction changes do, however, provide a useful simple method of monitoring the progress of development in synchronous cuvette cultures.

\section{Coulter counter analysis}

Typically, the volume distribution obtained from a heterogeneous culture of $R$. palustris was positively skewed, with a peak volume of about $0.38 \mu \mathrm{m}^{3}$ (Fig. 8). This was probably due to the tendency of cells to form clumps and rosettes. When dilutions of samples from a synchronous liquid culture of swarmers were analysed on the Coulter counter, volume distributions were initially very narrow when compared with the heterogeneous culture, with a peak of about $0.24 \mu \mathrm{m}^{3}$ (Fig. 8). As development proceeded the peak volume increased till division (at about $4.5 \mathrm{~h}$ in this experiment), when two peaks were seen, one corresponding to a mixture of swarmers and mother cells $\left(0.35 \mu \mathrm{m}^{3}\right)$ and the other to cells about to divide $\left(0.63 \mu \mathrm{m}^{3}\right)$. When division was complete, the resulting small-volume cells again commenced their volume increase. These post-divisional cells had a mean volume about $45 \%$ greater than the original selected swarmers. This was possibly due in part to the selection of smallerthan-average swarmers on the sucrose gradient but, more probably, was largely due to the presence of the larger mother cells together with the swarmers.

When changes in peak volume were plotted against time (Fig. 9) it became clear that there was little volume increase during swarmer maturation; however, the volume increase that followed this stage was linear.

Particle counts made on the synchronous culture sample dilutions (Fig. 9) again showed a very sharp increase in numbers at the time when division was observed. The doubling in numbers was not quite precise, presumably as a result of counting non-viable cells and non-bacterial particles. We have also obtained very similar results from viable counts made of synchronous liquid cultures. Some difficulty, however, was experienced in such analysis 


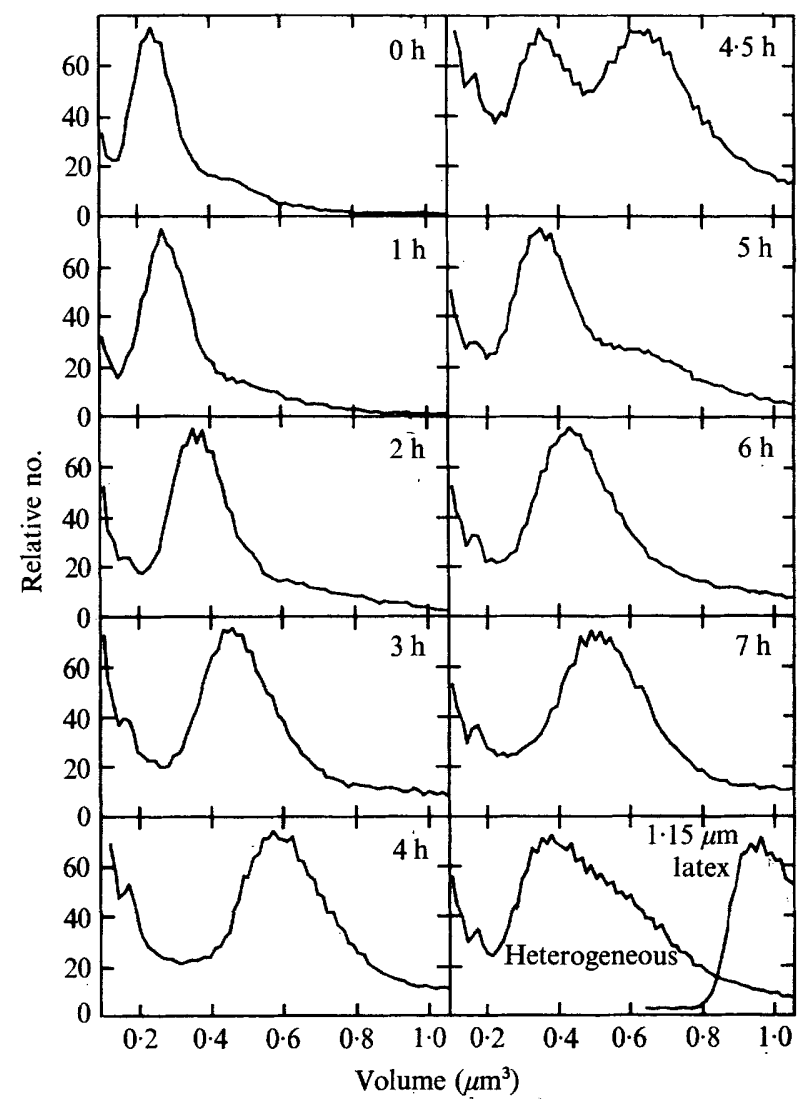

Fig. 8. Volume distribution of a synchronous culture of $R$. palustris. Samples were taken at intervals during the synchronous development and the volume distribution of suspended particles analysed using a Coulter counter and Channelyzer.

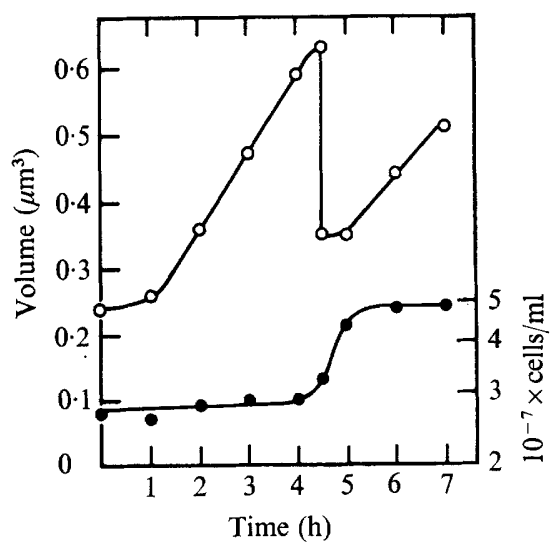

Fig. 9. Peak volume changes and total particle counts during a synchronous culture of $R$. palustris. The most frequent volumes observed in the distributions shown in Fig. 8 were plotted against time $(O)$, and also compared with particle counts $(\bullet)$ obtained on analysis of the same samples with the Coulter counter. 
of synchronous cultures. The synthesis of holdfast material by $R$. palustris gives rise to the characteristic rosettes of cells which could consequently lower the number of colony-forming units during plate counts. In addition, we have found that small-size debris (perhaps released holdfast material) can interfere with Coulter counter analysis. The results presented here were obtained using cells which had lost their motility and were synthesizing only small amounts of holdfast material, phenomena that were only observed after several subcultures of our strain of $R$. palustris under rapid growth conditions.

\section{DISCUSSION}

Populations of $R$. palustris swarmers, isolated by sucrose gradient sedimentation, exhibited excellent homogeneity and synchronous growth. Separation of swarmers resulted from their sedimentation velocity being much lower than that of cells developing tubes and buds or forming rosettes. This is a complete reversal of the distribution of swarmers and stalked cells observed after centrifuging Caulobacter cultures (Poindexter, I964).

The examination of numbers of individual cells in a microscope field of a synchronously growing swarmer slide culture, was a very sensitive method of observing the doubling of cell numbers. The sensitivity of the method permitted the two-step second generation to be clearly observed, even though we have found this to be difficult to demonstrate by viable or total counts of cells in samples from synchronous liquid culture (unpublished data). The two-step second generation and subsequent multiple cell number doublings give rise to a more rapid desynchronization than would normally be expected from such a homogeneous population. As a consequence, swarmer cultures of $R$. palustris only exhibit true synchrony during the first generation. Multiple division steps have similarly been observed in synchronous Caulobacter cultures (Degnen \& Newton, 1972) although they are not always evident in the synchronous growth curves (Staley \& Jordan, 1973).

Rhodopseudomonas palustris not only exhibited differentiation at the level of changes during its unusual cell cycle, but also by division to give two distinct cell types. The nonappendaged daughter swarmer cell was an immature and undeveloped form of its tubed mother cell. Maturation of swarmer cells usually occupied 30 to $35 \%$ of the division cycle. This compares closely with the proportions of the cycles spent in swarmer maturation in Hyphomicrobium (Moore \& Hirsch, 1973) and Rhodomicrobium (C. S. Dow \& R. Whittenbury, unpublished data). Rhodopseudomonas palustris swarmer maturation was characterized by a rapid increase in extinction, although there was no apparent increase in cell volume. These features and the ensuing holdfast synthesis, tube formation and loss of flagella are all phenomena unique to the developing swarmer cells. Once a daughter cell has carried out these developmental steps it becomes and remains a mother cell which will continue to give rise to successive daughter buds, apparently indefinitely. It would seem, therefore, that certain genes of the $R$. palustris chromosome are expressed only during swarmer maturation and tube elongation, and then never again. It is also essential that, immediately after separation of replicated nuclear material, differential control of the two chromosome copies must occur, such that one will continue to code for new daughter cells and the other will code for swarmer maturation and tube elongation.

Further studies of the cell cycle of synchronous $R$. palustris cultures should reveal information on how the sequential events in the cycle are temporally controlled. In addition, transcriptional and/or translational controls in the two classes of post-divisional cells might also be disclosed. 
We thank Professor R. Whittenbury and Dr C. S. Dow for their constant advice and encouragement. During the course of this work D.W. was in receipt of a studentship from the Medical Research Council.

\section{REFERENCES}

Degnen, S. T. \& Newton, A. (1972). Chromosome replication during development in Caulobacter crescentus. Journal of Molecular Biology 64, 671-680.

LEIFSON, E. (1964). Hyphomicrobium neptunium sp.n. Antonie van Leeuwenhoek 30, 249-256.

Mitchison, J. M. \& Vincent, W. S. (1965). Preparation of synchronous cell cultures by sedimentation. Nature, London 205, 987-989.

MoOre, R. L. \& HirsCH, P. (1973). First generation synchrony of isolated Hyphomicrobium swarmer populations. Journal of Bacteriology 116, 4I 8-423.

PoINDEXTER, J.S. (1964). Biological properties and classification of the Caulobacter group. Bacteriological Reviews 28, 23I-295.

Shapiro, L., Agabian-Keshishian, N. \& Bendis, I. (I971). Bacterial differentiation. Science, New York I73, 884-892.

Staley, J. T. \& Jordan, T. L. (I973). Crossbands of Caulobacter crescentus stalks serve as indicators of cell age. Nature, London 246, $155-156$.

Stove, J. L. \& StanieR, R. Y. (I962). Cellular differentiation in stalked bacteria. Nature, London I96, I I 89-I I 92.

WestmacotT, D. \& Primrose, S. B. (1975). An anaerobic bag for photoheterotrophic growth of some Rhodospirillaceae in Petri dishes. Journal of Applied Bacteriology 38, 205-207.

WhITTENBURY, R. \& MCLeE, A. G. (1967). Rhodopseudomonas palustris and Rh. viridis-photosynthetic budding bacteria. Archiv für Mikrobiologie 59, 324-334. 